\title{
Evaluation of a Diverse, Worldwide Collection of Wild, Cultivated, and Landrace Pepper (Capsicum annuum) for Resistance to Phytophthora Fruit Rot, Genetic Diversity, and Population Structure
}

\author{
R. P. Naegele, A. J. Tomlinson, and M. K. Hausbeck
}

Department of Plant, Soil and Microbial Sciences, Michigan State University, East Lansing 48824.

Accepted for publication 13 July 2014.

\begin{abstract}
Naegele, R. P., Tomlinson, A. J., and Hausbeck, M. K. 2015. Evaluation of a diverse, worldwide collection of wild, cultivated, and landrace pepper (Capsicum annuиm) for resistance to Phytophthora fruit rot, genetic diversity, and population structure. Phytopathology 105:110-118.

Pepper is the third most important solanaceous crop in the United States and fourth most important worldwide. To identify sources of resistance for commercial breeding, 170 pepper genotypes from five continents and 45 countries were evaluated for Phytophthora fruit rot resistance using two isolates of Phytophthora capsici. Genetic diversity and population structure were assessed on a subset of 157 genotypes using 23 polymorphic simple sequence repeats. Partial resistance and

3 and 5 days postinoculation (dpi). Plant introductions (PIs) 640833 and 566811 were the most resistant lines evaluated at 5 dpi to isolates 12889 and OP97, with mean lesion areas less than Criollo de Morelos. Genetic diversity was moderate (0.44) in the population. The program STRUCTURE inferred four genetic clusters with moderate to very great differentiation among clusters. Most lines evaluated were susceptible or moderately susceptible at $5 \mathrm{dpi}$, and no lines evaluated were completely resistant to Phytophthora fruit rot. Significant population structure was detected when pepper varieties were grouped by predefined categories of disease resistance, continent, and country of origin. Moderately resistant or resistant PIs to both isolates of $P$. capsici at $5 \mathrm{dpi}$ were in genetic clusters one and two.
\end{abstract} isolate-specific interactions were identified in the population at both
Phytophthora capsici Leonian is a devastating oomycete pathogen capable of causing disease on pepper (fruit and root rot and foliar blight). Pepper (Capsicum spp.) is an important vegetable commodity grown in temperate and tropical regions, with an estimated production of 25 million tons annually (United States Department of Agriculture [USDA] Economic Research Service). Sources of resistance to Phytophthora root rot have been identified in several small-fruited landrace Capsicum annuum and C. chinense lines $(7,24)$. Few studies have looked at Phytophthora fruit rot resistance, and no correlations between resistance to $P$. capsici-induced diseases in pepper have been identified $(3,39$, 41,43).

Phytophthora fruit rot, though less common than root rot, can be devastating when conditions are favorable $(14,15)$. Systemic fungicide applications, the predominant method of managing Phytophthora diseases, provide minimal protection to the fruit. No pepper cultivars or lines evaluated to date have demonstrated a complete resistance to Phytophthora fruit rot. Because morphological traits such fruit shape, color, size, and pungency are not predictive of susceptibility to Phytophthora fruit rot, reliable molecular markers are needed to incorporate resistance $(3,5,27)$. Identifying individuals with increased fruit rot resistance and molecular markers associated with that resistance will increase the probability of identifying and incorporating Phytophthora fruit rot resistance into commercial cultivars. A single quantitative trait loci (QTL) analysis in a recombinant inbred line (RIL) population identified minor and major QTL for fruit rot resistance in imma-

Corresponding author: M. K. Hausbeck; E-mail address: hausbec1 @ msu.edu

* The $\boldsymbol{e}$-Xtra logo stands for "electronic extra" and that the online version contains two supplemental tables.

http://dx.doi.org/10.1094/PHYTO-02-14-0031-R

(C) 2015 The American Phytopathological Society ture fruit (30). However, this study was limited to a single source of resistance, 'Criollo de Morelos'. Wild, landrace, and cultivated individuals from centers of origin and diversity can harbor genetic variability useful for enhancing fruit quality, disease resistance, and other agronomically important traits $(4,10,22,40)$.

Despite its current distribution around the world, cultivated pepper is a New World crop and consists of the intercrossing species $C$. annuum, $C$. chinense, $C$. frutescens, and $C$. baccatum $(1,16,33,34)$. C. annuum is the primary pepper species grown in the United States, and is thought to have originated in Mexico (16). The remaining species originated in other parts of Central and South America and are grown as vegetables, spices, and ornamentals $(2,13,16,29)$. The species diversity and worldwide distribution provide an excellent resource for identifying useful breeding materials.

Genetic diversity within pepper has been well-studied at a local level $(2,13,19,21,29,31,32,37,38)$. Domesticated populations of pepper (landraces and cultivars) have been evaluated and compared with wild (natural occurring) populations $(2,20,21$, $29,32,37,42)$. These studies have provided a valuable overview of the genetic diversity within specific regions but information on the diversity and population structure of pepper on a global basis is unknown.

When unaccounted, population structure can create false associations between markers and phenotypes $(8,9,23,45)$. Algorithms accounting for the population structure can result in fewer but stronger associations between the trait of interest and individual markers when properly applied $(6,46)$. In pepper, population structure has been evaluated among cultivated varieties (20) and within geographic regions $(29,31,32)$. In each of these studies, population structure was detected and could differentiate between geographic regions or market type (cultivated varieties), suggesting that great variation exists within the species $(1,2$, 20,32). Population studies among Capsicum spp. have shown that 
admixture is limited, with few ambiguous genotypes $(25,37,42)$. Furthermore, the association of population structure and genetic diversity with materials that have agronomic traits of interest (e.g., disease resistance) could provide a valuable tool for breeders and researchers.

The objectives of this study were to evaluate population structure, genetic diversity, and Phytophthora fruit rot resistance in a worldwide collection of $C$. annuum and determine whether population structure was associated with predefined categories of disease resistance, country, or continent of origin using polymorphic simple sequence repeat (SSR) markers.

\section{MATERIALS AND METHODS}

Plant material. In all, 170 genotypes of pepper germplasm (wild, cultivated, and landrace) were requested from the USDA Germplasm Resource Information Network (www.ars-grin.gov/) or commercial seed sources: Johnny's Select Seeds, Parks Seed, and Seedway (Supplemental Table 1). Pepper germplasm represented the known center of origin for pepper, regions of high diversity, and known root-rot-resistant material $(7,43)$. In total, 168 C. annuum lines, 1 C. frutescens (plant introduction [PI] 593920), and 1 C. chinense (PI 593929) were evaluated. Twenty seeds from each line were sown into 72-cell trays containing a soilless peat mix (Suremix Michigan Grower Products, Inc. Galesburg, MI) in a polyethylene greenhouse at the Michigan State University Horticulture Research Farm (East Lansing). Germinated seedlings were transferred to 4 -in. black plastic pots containing the same soilless peat mix and grown to maturity. Immature fruit were detached and bulked for each line. Fruit were taken to the laboratory for inoculation and subsequent evaluation.

Isolates. Two isolates were selected from the long-term collection of Dr. Mary K. Hausbeck (Michigan State University). Isolates were characterized by host, mefenoxam sensitivity (insensitive $=\mathrm{I}$ and sensitive $=\mathrm{S}$ ), and mating type (A1 or A2). Isolate 12889 (pepper, I, A1) and isolate OP97 (cucumber, S, A1) were maintained on unclarified V8 agar during the experiment. Prior to inoculations, isolates were activated by inoculating and recovering each isolate from a single pepper fruit.

Inoculation and evaluation. Pepper fruit were surface disinfested in $10 \%$ bleach for 5 min, rinsed with distilled water, and dried prior to inoculation. For inoculations, a single 6-mm plug of V8 agar from the actively growing isolate was placed, mycelium side down, onto the surface of the fruit. Plugs were covered with a sterile microcentrifuge tube cap and affixed into place with petroleum jelly. Pepper fruit were placed into a humidity chamber consisting of a clear, covered plastic box with a ring of moistened paper towel around the outside edge, and placed on a light bench under constant light at room temperature $\left(25^{\circ} \mathrm{C}\right)$. Pepper fruit were blocked by isolate and completely randomized within the boxes. Two control pepper fruit were inoculated with a sterile plug of V8 agar for each line. In all, five pepper fruit from each accession per isolate were evaluated and the experiment was performed three times for a total of 15 pepper fruit per isolate per line. Pepper landrace CM334 was used as the resistant control and Johnny's Breeding line JN571 was evaluated as the susceptible control. Due to poor fruit set, only two experimental replicates were performed on lines Grif 972, JN570, 262902, 339083, 511886, 593572, 631131, 631140, 640803, 182646,194261 , and197408 when inoculated with isolate OP97 and lines 194261, 182646, 164560, 640641 631131, 631126, 593572, 593511, 511882, 438633, 566811, 123469, 273415, JN570, and 224442 when inoculated with isolate 12889.

Pepper fruit were evaluated at 3 and 5 days postinoculation (dpi). Lesion area in square centimeters (maximum length by maximum width) was measured using a hand caliper. For some accessions, the visible lesion area was not solidly filled (e.g., multiple spots of diseased tissue interspersed with healthy tissue) and a coverage score was determined. If symptomatic tissue covered $<25 \%$ of the lesion area measured, the coverage score $=$ $0.25 ; 25$ to $<50 \%$, the coverage score was 0.5 ; if symptoms covered 50 to $<75 \%$, the score $=0.75$; and if the visible lesion coverage was $>75 \%$, the coverage score $=1$. For recovery of the isolates, isolations were performed on $\approx 10 \%$ of the symptomatic fruit. Three pieces of fruit were plated onto V8 agar amended with ampicillin, rifampicin, and benomyl (at $2 \mathrm{ml}, 2 \mathrm{ml}$, and $0.05 \mathrm{~g}$, respectively, per liter). Cultures of $P$. capsici were identified by morphological characteristics according to Waterhouse et al. (44). Mefenoxam sensitivity was confirmed by transferring isolates to V8 plates amended with mefenoxam at $100 \mathrm{ppm}$ and determining growth.

Statistical analyses. Control fruit (inoculated with sterile V8 plug) were removed prior to analysis to avoid violating variance assumptions. Experimental replicates were combined for statistical analysis. Final lesion area was calculated by multiplying the lesion area by the coverage score. Final lesion score for 3 and 5 dpi relative to line, country of origin, and host of origin was analyzed by analysis of variance using the PROC MIXED function of SAS v9.3. Line, isolate, and interaction means were separated using least significant difference at $P=0.05$, when significant. When analyzing unequal sample sizes, degrees of freedom were accounted using the Kenward Rogers option implemented in SAS. When analyzing by country, countries represented by fewer than four lines were removed from analyses. Data were $\log$ transformed for 3 -dpi values when analyzing by line and transformed $1 / x^{2}$, where $x$ indicates the line value at 3 and 5 dpi when analyzed by countries and continents to normalize the data. The percentage of diseased fruit was calculated by combining all replicates for a single line and isolate (total diseased out of 15 total pepper fruit). A diseased fruit was considered to be fruit with a visible lesion, regardless of lesion size.

Genetic analyses. Genomic DNA was extracted from young green leaves of pepper plants using the Nucleo Spin II DNA extraction kit (catalog number 740770; Machery-Nagel, Germany), according to the manufacturer's instructions. DNA was normalized to $10 \mathrm{ng} / \mu \mathrm{l}$ using the NanoDrop ND 1000 spectrophotometer and NanoDrop 2.4.7c software (NanoDrop Technologies Inc., Wilmington, DE).

In total, 192 primers from previously published SSR markers (28), solgenomics.org, or designed (Primer 3; http://primer3. sourceforge.net/) from putative Solanaceae defense-related genes (National Center for Biotechnology Information; ncbi.nlm. nih.gov) were tested against a subset of the pepper collection to identify polymorphic markers. Reactions were performed in $15 \mu \mathrm{l}$ of total volume and contained $1 \mu \mathrm{l}$ of DNA and $0.15 \mu \mathrm{l}$ of GoTaq (Promega Corporation, Madison, WI), $0.9 \mu \mathrm{l}$ of $25 \mu \mathrm{M} \mathrm{MgCl}$, $0.3 \mu \mathrm{l}$ of dNTPs, and $0.6 \mu \mathrm{l}$ each of forward and reverse primers (Integrated DNA Technologies, Inc.), with $8.45 \mu$ l of doubledistilled $\mathrm{H}_{2} \mathrm{O}$. PCR reactions were performed in a programmable thermal cycler (Eppendorf, Westbury, NY) using a program of initial denaturation at $94^{\circ} \mathrm{C}(3 \mathrm{~min})$; followed by 35 cycles at $94^{\circ} \mathrm{C}(30 \mathrm{~s}), 60^{\circ} \mathrm{C}(30 \mathrm{~s})$, and $72^{\circ} \mathrm{C}(1 \mathrm{~min})$; with a final extension step of $10 \mathrm{~min}$ at $72^{\circ} \mathrm{C}$. PCR products were analyzed by electrophoresis in $4 \%(\mathrm{wt} / \mathrm{vol})$ agarose gel in $1 \times$ Tris-borate-EDTA buffer, stained with ethidium bromide $(5 \mu \mathrm{g} / \mathrm{ml})$ for visualization and compared with a 100-bp ladder (Invitrogen Life Technologies, Burlington, ON, Canada) to determine amplicon sizes. SSR markers identified as polymorphic in the population were used for genetic diversity and population structure analyses (Table 1).

Genetic diversity and population structure. Genetic diversity was estimated using Powermarker v3.25 (26) and significance at each locus was determined with 1,000 permutations using the Exact test; overall genetic diversity was estimated using the Mantel test as implemented in Powermarker.

Population structure of the germplasm was analyzed using STRUCTURE v2.3.4 (35). Following preliminary analyses, burnin 
length, MCMC chain replication, and lambda were selected to be 200,000, 500,000 and 0.49, respectively. Population number (k) was determined empirically by comparing posterior distribution likelihoods independently among three independent runs of $\mathrm{K}=1$ to 20, as described by Evanno et al. (11). Data included 23 polymorphic SSRs and were analyzed using the admixture model and correlated allele frequencies without previous population information $(12,35)$. Fst significance between populations was determined using $95 \%$ confidence intervals based on 1,000 bootstrap replicates, as implemented in Powermarker.

Visualization of the resulting proportion of membership (Q) of each individual into predefined categories (country, continent, and disease susceptibility) was generated using the Population Sorting Tool in $\mathrm{R}$ (36). Individuals with $\mathrm{Q} \geq 0.6$ membership in a single subpopulation were labeled as such. Individuals with $\mathrm{Q}<0.6$ membership in a single subpopulation were considered admixed. Significant population structure by continent, country, and Phytophthora fruit rot resistance was estimated using the population differentiation test implemented in Powermarker. Significance at each locus and overall was determined using 1,000 permutations. Countries represented by fewer than four individuals were excluded from analyses. Significance of pairwise Fst differentiation was based on 2.5 and $97.5 \%$ confidence intervals calculated from 1,000 bootstrap replications. At $3 \mathrm{dpi}$, fruit were grouped into resistant (lesion area 0 to $2 \mathrm{~cm}^{2}$ ), moderately resistant ( 2 to $5 \mathrm{~cm}^{2}$ ), moderately susceptible $\left(5\right.$ to $\left.10 \mathrm{~cm}^{2}\right)$, and susceptible $\left(\geq 10 \mathrm{~cm}^{2}\right)$ categories. At $5 \mathrm{dpi}$, fruit categories were resistant $\left(0\right.$ to $\left.5 \mathrm{~cm}^{2}\right)$, moderately resistant $\left(5\right.$ to $\left.10 \mathrm{~cm}^{2}\right)$, moderately susceptible (10 to $\left.20 \mathrm{~cm}^{2}\right)$, and susceptible $\left(\geq 20 \mathrm{~cm}^{2}\right)$.

\section{RESULTS}

Phytophthora fruit rot. Significant differences were identified among pepper genotypes at both 3 and 5 dpi. At 3 dpi, isolate was not significant $(P=0.319)$ and line was highly significant $(P<$ $0.001)$. Line-isolate interactions were also significant $(P=$ $0.0001)$ at $3 \mathrm{dpi}$. Breeding line JN571 was the most susceptible, with an average lesion area of 27 and $30 \mathrm{~cm}^{2}$ for isolates 12889 and OP97, respectively. When inoculated with isolate OP97, line PI 640516 had the smallest average lesion area of $0 \mathrm{~cm}^{2}$. When inoculated with 12889, line PI 640803 had the lowest lesion area $\left(0 \mathrm{~cm}^{2}\right)$. Most lines, 111 and 121 for isolates 12889 and OP97, respectively, were moderately resistant or resistant to $P$. capsici at 3 dpi.

Significant line-isolate interactions $(P=0.0008)$ were identified at 5 dpi. Line was highly significant $(P<0.0001)$ and isolate was not significant $(P=0.302)$. Most genotypes evaluated were susceptible to both isolates: 74 lines for isolate OP97 and 103 for 12889 (Supplemental Table 2). No accession was completely resistant to both isolates of $P$. capsici. JN571 had an average lesion area of $50 \mathrm{~cm}^{2}$, indicating that the fruit were completely covered by the lesion. CM334, the resistant control, had an average lesion area of 14 and $17 \mathrm{~cm}^{2}$ when inoculated with isolates 12889 and OP97, respectively. One line, PI 566811, had an average lesion area of $1 \mathrm{~cm}^{2}$ and was significantly more resistant than CM334 when inoculated with OP97. This same line had a lesion area of $3.8 \mathrm{~cm}^{2}$ when inoculated with isolate 12889 .

When analyzed by country and continent of origin, significant differences were evident at 3 and 5 dpi (Tables 2 and 3). Country was highly significant $(P<0.0001)$, isolate was also significant $(P<0.0001$ and $P=0.007)$, and the interaction between country and isolate was not significant $(P=0.3448$ and $P=0.0581)$ at 3 and 5 dpi. Fruit from Pakistan were the least susceptible, while fruit from Serbia were the most susceptible at both 3 and 5 dpi. When analyzed by continent, significant interactions $(P=0.0369$ and 0.0269) were detected between continent and isolate at 3 and 5 dpi, respectively. Isolate OP97 was significantly more virulent than isolate 12889 at both 3 and 5 dpi. At 3 dpi, fruit from Africa and South America were the least susceptible when inoculated with OP97 and 12889, respectively. Fruit from Europe were the most susceptible when inoculated with 12889 or OP97 3 dpi. At 5 dpi, fruit from Africa and South America were the least susceptible and fruit from Europe were the most susceptible when inoculated with OP97 and 12889, respectively (Table 3).

The percentage of diseased fruit varied greatly (13 to $100 \%$ incidence) between lines and isolates at 5 dpi. Most lines evaluated had incidence $>50 \%$ (150 and 148 for isolates 12889 and OP97, respectively). When inoculated with isolate 12889 , line 640803 had the lowest incidence, with $30 \%$ diseased fruit. CM334 had a disease incidence of 93\%. Line JN571 had 100\%

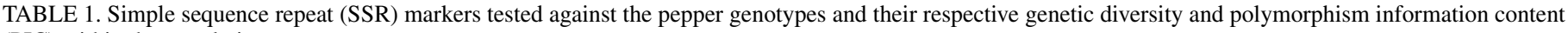
(PIC) within the population

\begin{tabular}{|c|c|c|c|c|c|}
\hline \multirow{2}{*}{$\frac{\text { SSR }}{\text { E492334 }}$} & \multicolumn{2}{|c|}{ Primer sequence } & \multirow{2}{*}{$\begin{array}{c}\text { Sourcey }^{y} \\
\text { SOLCAP }\end{array}$} & \multirow{2}{*}{$\begin{array}{c}\begin{array}{c}\text { Genetic } \\
\text { diversity }\end{array} \\
0.51\end{array}$} & \multirow{2}{*}{$\frac{\mathrm{PIC}^{\mathrm{Z}}}{0.44}$} \\
\hline & GCTGGTTGTGGTTGTACGAG & TGCTCACATATCAATAGATTCAGC & & & \\
\hline $\mathrm{U} 221402$ & AAGCCTCCTTGACAAATGCATATAG & AGATATAGCTACAGTGGCAGCTTCATC & SOLCAP & 0.57 & 0.52 \\
\hline T0633 & GATGGGCTATGCTTGCTGTT & ACATCCCCAATGTTGTTGTG & SOLCAP & 0.26 & 0.24 \\
\hline C2_At2g30100 & CAAACTATTTCAGATTTACACTTAAATG & ACCGTTCAAGTTGGCTCTTCACAACAG & SOLCAP & 0.24 & 0.22 \\
\hline CA $\overline{5} 16044$ & АТСТTСТТСТСАТТТСТСССТTС & TGCTCAGCATTAACGACGTC & SOLCAP & 0.63 & 0.58 \\
\hline asu5 & GGAAGATCCCTTGAATGAGTATGTCTC & GGCTGAAAATGTCTGATGGAACTGG & SOLCAP & 0.33 & 0.31 \\
\hline GPMS159 & AAGAACATGAGGAACTTTAACCATG & TTCACCCTTCTCCGACTCC & SOLCAP & 0.38 & 0.32 \\
\hline GP20117 & TGACAGCTACCGAAAATGA & CCTCTAATGCTGACGTGAA & SOLCAP & 0.49 & 0.45 \\
\hline CP10023 & CACCATGTAGCATCTGGG & GATGGATGGATCGACAGA & SOLCAP & 0.48 & 0.44 \\
\hline GP1127 & CACCACCAGTCACAAAGTTAC & СССТTCAAATACATCCCATGC & SOLCAP & 0.54 & 0.46 \\
\hline CA515275 & СТCTGCССТССТСАACCC & AAAATATGGTCGGAGATCCG & SOLCAP & 0.21 & 0.20 \\
\hline CP10023 & CACCATGTAGCATCTGGG & GATGGATGGATCGACAGA & SOLCAP & 0.55 & 0.52 \\
\hline GP20087 & СССТСТССТСААТТСАСА & ССТTTAССССТАAАTTTGAT & SOLCAP & 0.28 & 0.26 \\
\hline GQ386945 & GCTGCTATGCCCCCAAGGAT & TTTCTAGACAAGGCAGCTCACCAAT & NCBI & 0.26 & 0.25 \\
\hline AF348141 & CCTTACGGGGAAAACCTAGC & CCATACGGACGTTGTCCTCT & NCBI & 0.64 & 0.57 \\
\hline EF645679 & GCGCGAGAGACTACAAATCC & CACTCCTTCGTATCCCTCCA & NCBI & 0.62 & 0.54 \\
\hline EF100893 & GTTTGGTCTTGTGGGGTCAC & GGCTTTTCTCCACCATTCAC & NCBI & 0.29 & 0.27 \\
\hline GU295217 & TTTCGGATTGCCCTATGCTTGTT & AAATTTGTGAGGGCTGTTAGGT & NCBI & 0.14 & 0.13 \\
\hline GU116570 & ATTCGGGGTGTGATGAGGTGGAG & AAAAACAAACATAGGGCAAGACGAA & NCBI & 0.13 & 0.12 \\
\hline HPMSHSMADS & TGCTTTCAAAACAATTTGCATGG & GCGTCTAATGCAAAACACACATTAC & 28 & 0.70 & 0.65 \\
\hline CAMS319 & TCACCTTCCACAGCATCAAG & CAAACGCAAACACCAATCAG & 28 & 0.50 & 0.42 \\
\hline CAMS839 & GCAAGCACATCATGCTGAAT & CGAGCGCATTATTGAAGTGA & 28 & 0.61 & 0.57 \\
\hline C2_At5g13200 & TATGGGTCCGCCTGCAGTTCCAAC & AAGTTTTCCCCATGCCGCTTCTGT & SOLCAP & 0.75 & 0.71 \\
\hline
\end{tabular}

y SOLCAP = Solanaceae Coordinated Agricultural Project; and NCBI = National Center for Biotechnology Information.

z PIC for each marker. 
disease incidence, as did 32 other lines. When inoculated with isolate OP97, line 640582 had the lowest disease incidence, with $13 \%$ of fruit infected. CM334 had a disease incidence of $53 \%$. JN571 had 100\% disease incidence, along with 18 other lines.

Population structure analysis. The 192 SSRs evaluated yielded 23 polymorphic markers that were used for characterizing and evaluating population structure of the pepper collection. Population structure for 157 of the 170 genotypes was estimated using the Bayesian analysis software STRUCTURE (35). Of the 170 lines, 13 were removed due to poor marker reproducibility. Pepper lines were grouped into four genetic clusters $(\mathrm{Ln}=-5058)$ according to STRUCTURE. The two $C$. frutescens and $C$. chinense accessions were solely placed into genetic cluster 3 , whereas $C$. annuum individuals were distributed through each of clusters (Fig. 1). In total, 142 individuals could be assigned to a single cluster based on membership. The remaining 15 individuals could not be assigned to a single cluster and were classified as admixed, denoted as cluster 5. For the STRUCTURE inferred clusters,

TABLE 2. Capsicum spp. Phytophthora fruit rot resistance among countries of origin

\begin{tabular}{lcl}
\hline & \multicolumn{2}{c}{ Lesion area $\left(\mathrm{cm}^{2}\right)^{\mathrm{z}}$} \\
\cline { 2 - 3 } Country & $3 \mathrm{dpi}$ & \multicolumn{1}{c}{$5 \mathrm{dpi}$} \\
\hline Pakistan & $5.66 \mathrm{~A}$ & $19.44 \mathrm{~A}$ \\
Ethiopia & $9.21 \mathrm{AB}$ & $25.56 \mathrm{BC}$ \\
Mexico & $7.58 \mathrm{~B}$ & $23.64 \mathrm{~B}$ \\
Colombia & $9.71 \mathrm{~B}$ & $27.41 \mathrm{BCD}$ \\
Guatemala & $5.89 \mathrm{~A}$ & $33.01 \mathrm{BCDE}$ \\
India & $9.47 \mathrm{BC}$ & $31.28 \mathrm{CDE}$ \\
Brazil & $10.13 \mathrm{CD}$ & $29.55 \mathrm{BCDE}$ \\
Iran & $10.78 \mathrm{D}$ & $32.60 \mathrm{DEF}$ \\
Spain & $4.88 \mathrm{BC}$ & $29.44 \mathrm{EFG}$ \\
United States & $8.81 \mathrm{E}$ & $33.16 \mathrm{FGH}$ \\
Turkey & $13.69 \mathrm{E}$ & $36.78 \mathrm{FGH}$ \\
Soviet & $7.61 \mathrm{E}$ & $38.62 \mathrm{HI}$ \\
China & $11.23 \mathrm{E}$ & $34.55 \mathrm{GHI}$ \\
Serbia & $18.82 \mathrm{~F}$ & $43.72 \mathrm{I}$ \\
\hline
\end{tabular}

${ }^{y}$ Categories with fewer than four individuals representing a country were not included in analyses.

${ }^{z}$ Mean lesion area for both isolates combined at 3 and 5 days postinoculation ( 3 and 5 dpi, respectively); different letters within an inoculation time indicate significant differences using least significant difference at $P=0.05$. Statistics were performed on transformed data and mean values are presented. mean Fsts varied from 0.12 to 0.45 . Cluster 1 had moderate, very great, and little differentiation from clusters 2, 3, and 4, respectively. Cluster 2 had moderate and very great differentiation from cluster 3 and cluster 4, respectively. Cluster 3 had very great differentiation from cluster 4, according to Hartl and Clark (18).

When individual genotypes were grouped by continent and country of origin, species, or diseases resistance, population structure was detected. Significant differences were detected among individual markers and the predefined categories. No clusters were perfectly correlated with predefined categories but some clusters were more frequently found in some categories. Predefined categories represented by fewer than four individuals were removed from analyses to limit spurious relationships (17). Cluster 3 individuals were only represented in South America and Africa, and cluster 1 individuals were less prevalent in Africa and South America (Fig. 2). Cluster 2 individuals were less prevalent in Africa but constituted a higher proportion of the individuals from Europe, South America, and Asia. Cluster 4 individuals were a low proportion of individuals from Europe and South America. Among countries, variation in cluster representation was more evident than among continents (Fig. 3). Individuals in cluster 1 were not found in China, Colombia, or Spain. Individuals from cluster 2 were not found in Brazil or China. Cluster 3

TABLE 3. Capsicum spp. Phytophthora fruit rot resistance among continents of origin

\begin{tabular}{lcclll}
\hline & \multicolumn{3}{c}{ Lesion area $\left(\mathrm{cm}^{2}\right)$ per isolate } \\
\cline { 2 - 3 } \cline { 5 - 6 } \cline { 5 - 6 } Continent $^{\mathrm{y}}$ & \multicolumn{2}{c}{$3 \mathrm{dpi}$} & \multicolumn{2}{c}{$5 \mathrm{dpi}$} \\
\cline { 2 - 3 } & 12889 & OP97 & & 12889 & OP97 \\
\hline Africa & $10.29 \mathrm{BCD}$ & $5.89 \mathrm{~A}$ & & $33.10 \mathrm{BC}$ & $23.31 \mathrm{~A}$ \\
Asia & $9.28 \mathrm{C}$ & $7.77 \mathrm{BC}$ & & $30.50 \mathrm{BC}$ & $30.71 \mathrm{BC}$ \\
Europe & $14.28 \mathrm{E}$ & $11.50 \mathrm{D}$ & & $39.88 \mathrm{D}$ & $35.67 \mathrm{C}$ \\
North America & $8.26 \mathrm{C}$ & $7.84 \mathrm{BC}$ & & $29.34 \mathrm{~B}$ & $28.39 \mathrm{~B}$ \\
South America & $9.79 \mathrm{BC}$ & $9.49 \mathrm{~B}$ & & $28.84 \mathrm{~B}$ & $28.17 \mathrm{~B}$ \\
\hline
\end{tabular}

${ }^{\mathrm{y}}$ Categories with fewer than four individuals representing a country were not included in analyses.

${ }^{\mathrm{z}}$ Mean lesion area for both isolates combined at 3 and 5 days postinoculation ( 3 and 5 dpi, respectively); different letters within an inoculation time indicate significant differences using least significant difference at $P=0.05$. Statistics were performed on transformed data and mean values are presented.

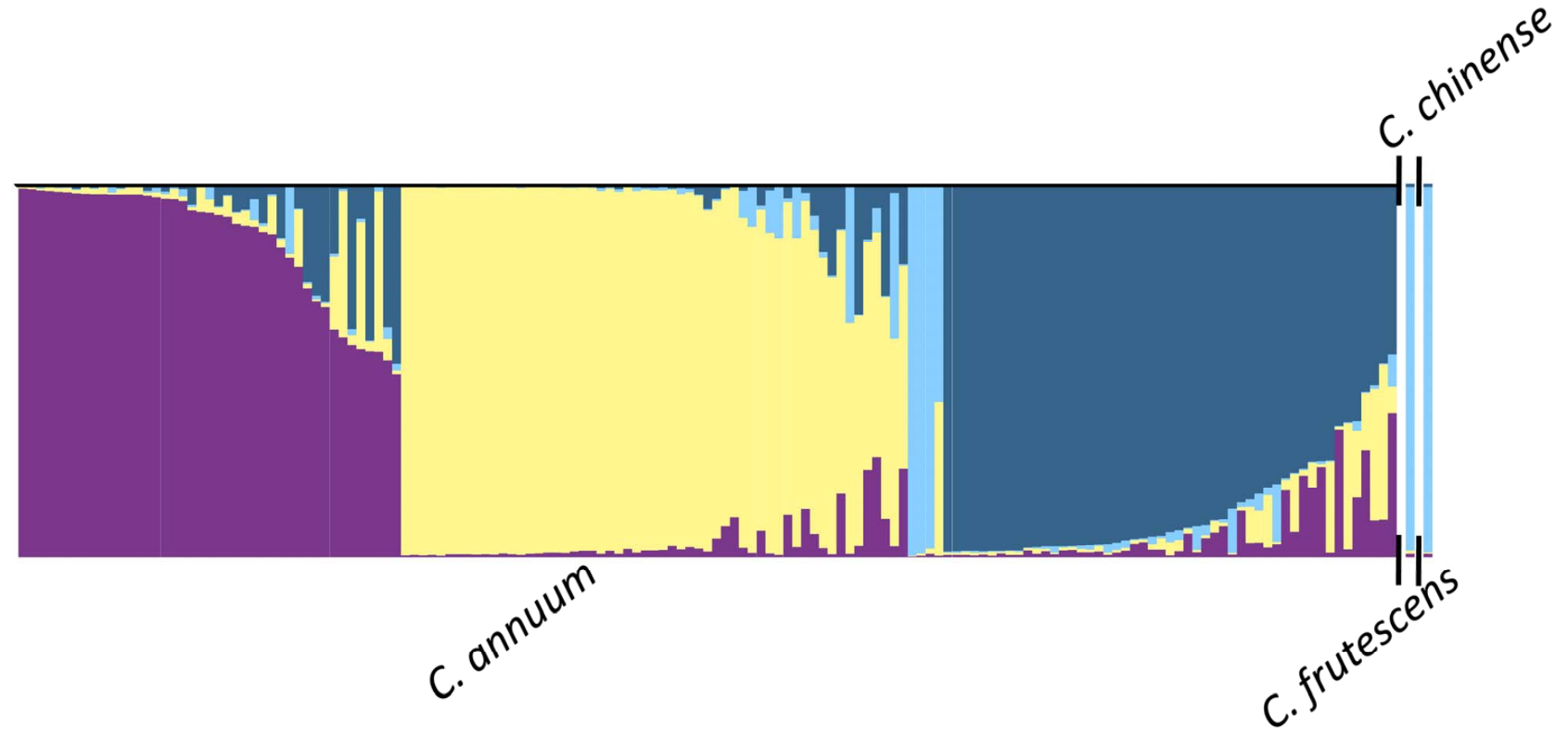

Fig. 1. Population structure grouped by species. Cluster 1 (purple/black), cluster 2 (light yellow/light gray), cluster 3 (sky blue/gray), and cluster 4 (steel blue/dark gray). 
individuals were not found in any of the countries represented by at least four lines. Cluster 4 was only represented in individuals from Brazil, China, India, Mexico, Turkey, and the United States.

At 3 dpi, each cluster was represented in the resistant category for isolates OP97 and 12889. When grouped by disease resistance for both isolates at $5 \mathrm{dpi}$, individuals from clusters 3 and 4 were not represented in the moderately resistant or resistant categories and cluster 2 had a low prevalence in the resistant or moderately resistant categories for isolate 12889 (Figs. 4 and 5).

Diversity of SSR loci in the pepper germplasm collection. In total, 102 alleles were detected among the 23 SSRs evaluated in the collection, ranging from 2 to 7 alleles per locus, with an average allele diversity of 4.9 alleles per locus. The mean genetic diversity index of the collection was 0.44 . The mean polymorphism information content (PIC) value was 0.40 for the collection, and individual markers ranged from 0.12 to 0.71 for the population (Table 1). When individual genotypes were evaluated, the highest PIC value was 0.54 in PI 640809 and the lowest PIC value was 0.03 in lines JN566, PI 148628, and PI 640803. Genetic diversity was distributed similarly within continents (0.38 to 0.47$)$, and pairwise Fsts indicated little to moderate differentiation among continents $(0.00$ to 0.07$)$ (Tables 4 and 5). Individuals from North America, Asia, and South America had the highest genetic diversity and genetic differentiation was highest in individuals from North America. Genetic diversity within countries varied greatly $(0.26$ to 0.45$)$ and pairwise Fst values detected little to very great genetic differentiation among countries (Tables 4 and 5). Genetic diversity was highest in individuals from Iran, Mexico, and the United States. The greatest differentiation was seen when comparing other countries with individuals from Mexico and the United States (Tables 5 and 6).

Pairwise Fsts for disease resistance at 3 and 5 dpi to 12889 and OP97 showed little to very great (0 to 0.50$)$ genetic differentiation between categories (Table 7). When inoculated with isolate OP97, no significant genetic differentiation was evident between any of the categories at $3 \mathrm{dpi}$. At $5 \mathrm{dpi}$, individuals in the resistant or moderately resistant (R/MR) category and the susceptible (S) category were significantly differentiated, as were individuals in the moderately susceptible (MS) and R/MR categories. When inoculated with 12889, differentiation between categories was significant at 3 dpi for MS and MR categories and MS and S categories. Significant differentiation was detected at 5 dpi between the MR and S, MS and S, the MR and MS categories at 3 dpi when inoculated with OP97.

\section{DISCUSSION}

Pepper is an important crop cultivated around the world, and $P$. capsici is a devastating pathogen that causes economic losses

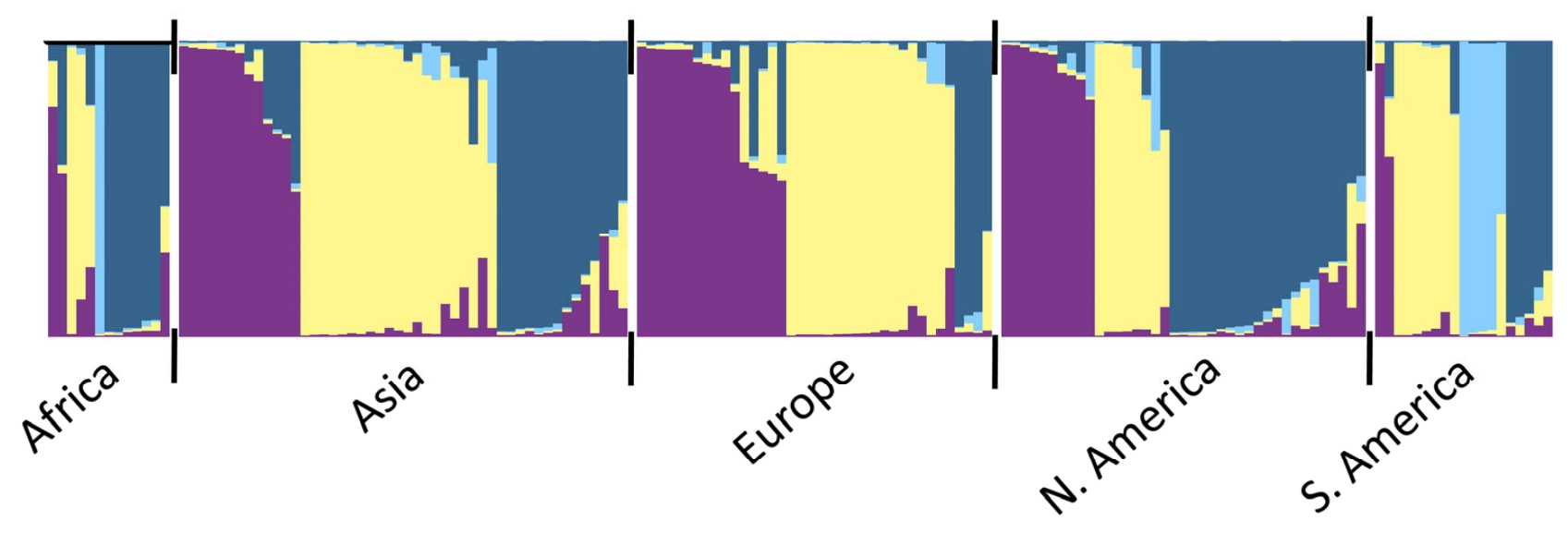

Fig. 2. Population structure grouped by continent of origin for pepper germplasm. Cluster 1 (purple/black), cluster 2 (light yellow/light gray), cluster 3 (sky blue/gray), and cluster 4 (steel blue/dark gray). A white space and black tick marks separate subgroups of individuals.

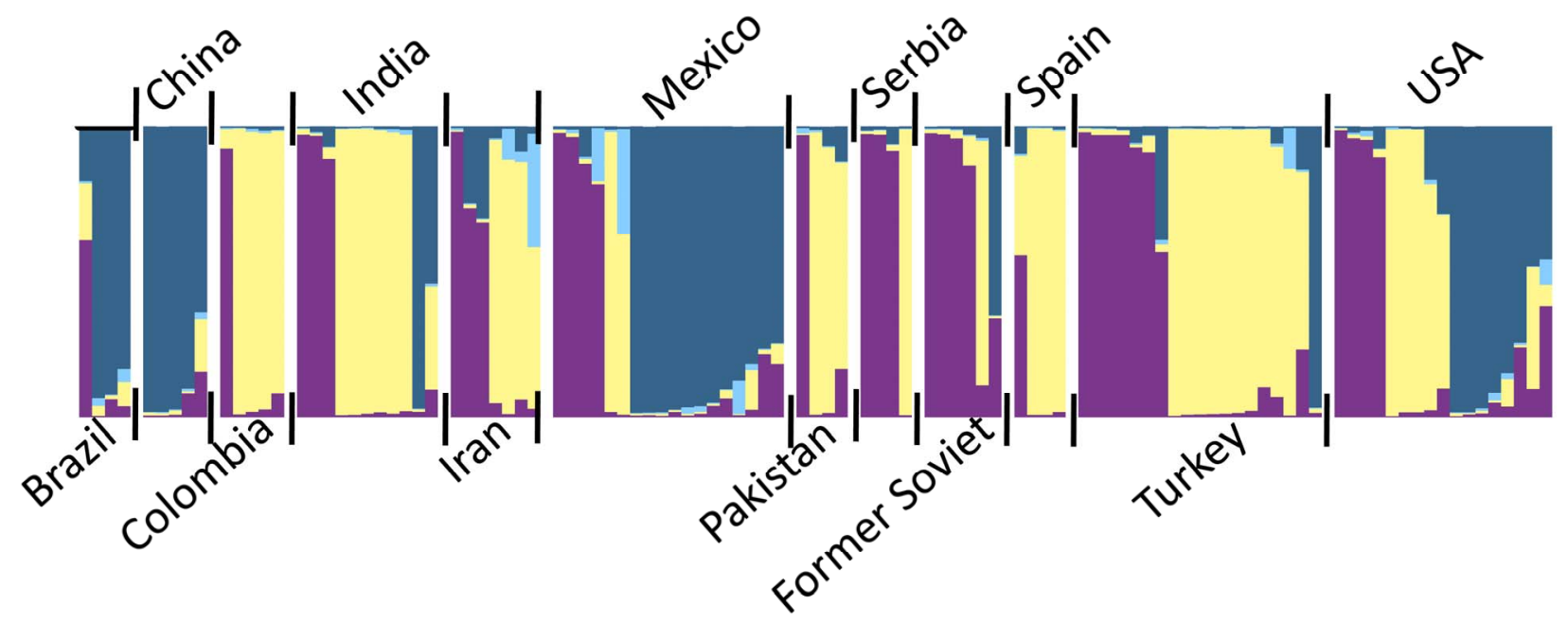

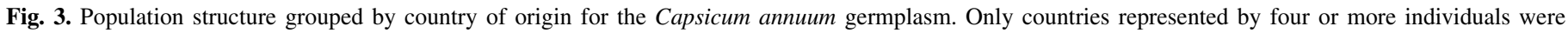

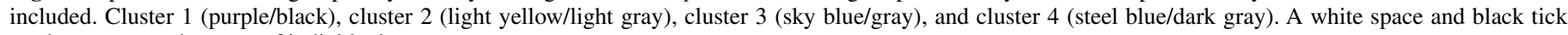
marks separate subgroups of individuals. 
annually on it. In this study, we evaluated Phytophthora fruit rot resistance, population structure, and genetic diversity of a diverse collection of pepper fruit from around the globe. Significant differences among lines were detected for disease resistance and significant population structure was detected when grouped by predefined categories of disease resistance, country, and continent of origin.

Most pepper accessions in this study were highly susceptible to both isolates of $P$. capsici at 5 dpi. At 5 dpi, disease incidence varied greatly among lines, and lines with partial resistance often
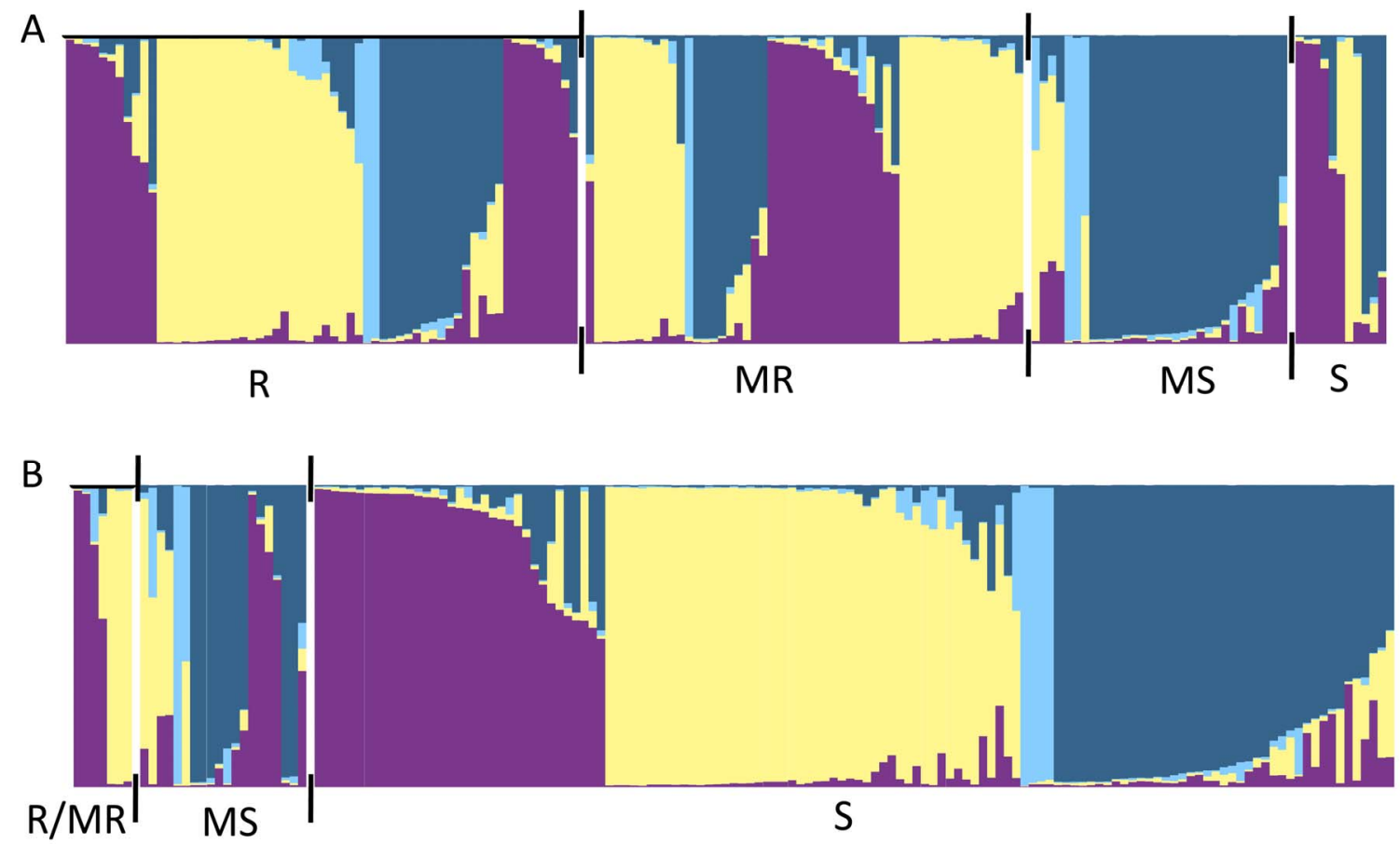

Fig. 4. Population structure grouped by Phytophthora fruit rot resistance to isolate OP97 at $\mathbf{A}, 3$ days postinoculation and $\mathbf{B}, 5$ days postinoculation. Individuals were grouped into a resistant and moderately resistant category (R/MR), a moderately susceptible category (MS), and a susceptible category (S) based on their mean disease ratings. Cluster 1 (purple/black), cluster 2 (light yellow/light gray), cluster 3 (sky blue/gray), and cluster 4 (steel blue/dark gray). A white space and black tick marks separate subgroups of individuals.
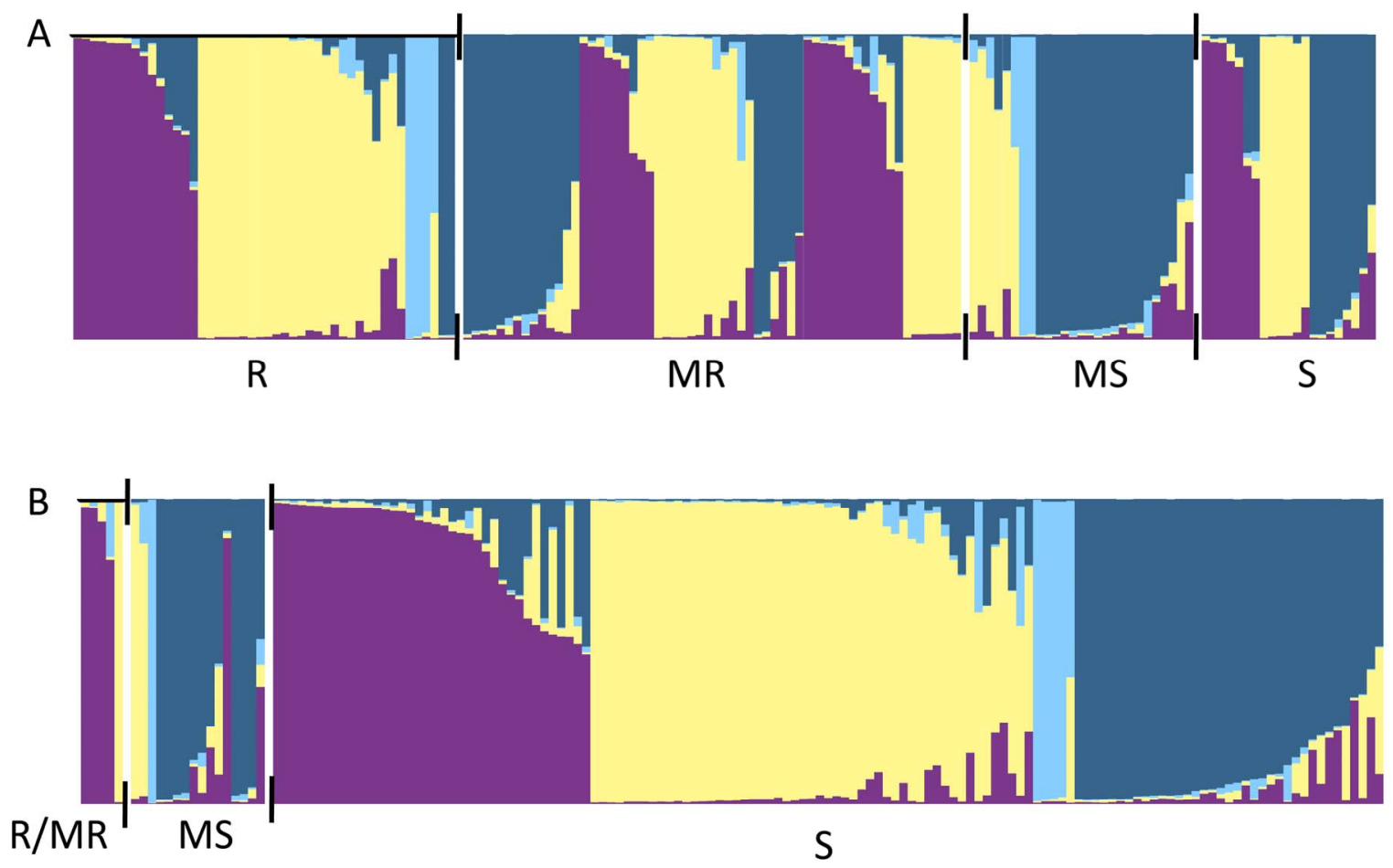

Fig. 5. Population structure grouped by Phytophthora fruit rot resistance to isolate 12889 at $\mathbf{A}, 3$ days postinoculation and $\mathbf{B}, 5$ days postinoculation. Individuals were grouped into a resistant and moderately resistant category (R/MR), a moderately susceptible category (MS), and a susceptible category (S) based on their mean disease ratings. Cluster 1 (purple/black), cluster 2 (light yellow/light gray), cluster 3 (sky blue/gray), and cluster 4 (steel blue/dark gray). A white space and black tick marks separate subgroups of individuals. 
had lower incidence than the most susceptible lines. The resistant control, CM334, had a moderate to high incidence of fruit rot and a moderate mean lesion area, 14 and $17 \mathrm{~cm}^{2}$, depending on the isolate. The susceptible control JN571 also had a high incidence of disease, and lesion area was high $\left(\approx 50 \mathrm{~cm}^{2}\right)$.

Several lines were identified with greater resistance or lower incidence than CM334 and are potential sources of resistance for breeding programs. PIs 201237, 640833, and 566811 had lesion areas smaller than CM334 for isolates OP97 and 12889. In addition, lines PI 201237 and 566811 have previously been reported to have moderate resistance to Phytophthora root rot, and

TABLE 4. Genetic diversity of pepper genotypes among countries and continents

\begin{tabular}{lll}
\hline & \multicolumn{2}{c}{ Diversity estimates $^{\mathrm{z}}$} \\
\cline { 2 - 3 } Category & $\mathrm{G}_{\mathrm{D}}$ & $\mathrm{PIC}$ \\
\hline Continent & & \\
Africa & 0.40 & 0.36 \\
Asia & 0.44 & 0.39 \\
Europe & 0.38 & 0.34 \\
North America & 0.47 & 0.43 \\
South America & 0.41 & 0.37 \\
Country & & \\
Afghanistan & 0.28 & 0.23 \\
Brazil & 0.35 & 0.27 \\
China & 0.35 & 0.29 \\
Colombia & 0.27 & 0.22 \\
Former Soviet & 0.35 & 0.29 \\
India & 0.34 & 0.29 \\
Iran & 0.43 & 0.38 \\
Mexico & 0.45 & 0.41 \\
Pakistan & 0.36 & 0.30 \\
Serbia & 0.26 & 0.22 \\
Spain & 0.27 & 0.22 \\
Turkey & 0.36 & 0.31 \\
\hline
\end{tabular}

y Categories represented by fewer than four lines were excluded from analyses and are not shown.

${ }^{\mathrm{z}}$ Average values for simple sequence repeats are presented; mean values are presented for the genetic diversity $\left(\mathrm{G}_{\mathrm{D}}\right)$ and the polymorphism information content (PIC). have larger fruit than CM334 (7,27). PI GRIF 9109 and PI 250141 had lower disease incidence than CM334 $(\leq 47 \%)$ when inoculated with 12889 or OP97, and no reported history of root rot resistance. These inoculations were made under ideal disease conditions, and lines with lower incidence may prove to be more resistant under field conditions. None of the lines evaluated were completely resistant to Phytophthora fruit rot at $5 \mathrm{dpi}$; this included all lines with known resistance to Phytophthora root rot (7). These results are consistent with previous studies that have shown that other Phytophthora diseases are inherited separately $(41,43)$.

Genetic diversity within this collection of $C$. annuum was moderate (0.44), and most individuals were grouped into one of four genetic clusters based on the Bayesian analysis. Genetic diversity was highest in the center of origin for $C$. annuum, Mexico, and lowest in Serbia. Genetic clusters did not completely correspond with predefined categories of continent, country, or

TABLE 7. Genetic differentiation (Fst pairwise differentiation) among pepper disease resistance categories 3 (shaded values) and 5 days postinoculation (dpi) when inoculated with OP97 and 12889

\begin{tabular}{|c|c|c|c|c|}
\hline \multirow[b]{2}{*}{ Category ${ }^{y}$} & \multicolumn{4}{|c|}{ Pairwise $\mathrm{Fst}^{\mathrm{z}}$} \\
\hline & MR & MS & $\mathrm{R}$ & $\mathrm{S}$ \\
\hline \multicolumn{5}{|c|}{ Isolate OP97 } \\
\hline MR & & 0.01 & 0.01 & 0.05 \\
\hline MS & 0.18 & $\ldots$ & 0.01 & 0.04 \\
\hline $\mathrm{R}$ & & $\ldots$ & $\ldots$ & 0.04 \\
\hline $\mathrm{S}$ & $0.50 *$ & $0.00 *$ & $\ldots$ & $\ldots$ \\
\hline \multicolumn{5}{|c|}{ Isolate 12889} \\
\hline MR & 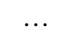 & $0.01 *$ & 0.01 & $0.02 *$ \\
\hline MS & $0.12 *$ & $\ldots$ & 0.03 & $0.01 *$ \\
\hline $\mathrm{R}$ & $\ldots$ & $\ldots$ & $\ldots$ & 0.03 \\
\hline $\mathrm{S}$ & 0.49 & $0.00 *$ & $\ldots$ & $\ldots$ \\
\hline
\end{tabular}

y Values for 3 dpi are bold above the diagonal and 5 dpi are below the diagonal for OP97 and 12889.

${ }^{\mathrm{z}}$ Average values for simple sequence repeats are presented; * indicates value was outside the $95 \%$ confidence interval at 1,000 bootstraps. MS = moderately susceptible, $\mathrm{R}=$ resistant, $\mathrm{MR}=$ moderately resistant, and $\mathrm{S}=$ susceptible.

TABLE 5. Genetic differentiation (Fst pairwise differentiation) of pepper genotypes among countries

\begin{tabular}{|c|c|c|c|c|c|c|c|c|c|c|c|}
\hline \multirow[b]{2}{*}{ Country ${ }^{y}$} & \multicolumn{11}{|c|}{$\mathrm{Fst}^{\mathrm{z}}$} \\
\hline & Afghanistan & Brazil & China & Colombia & Former Soviet & India & Iran & Mexico & Pakistan & Serbia & Spain \\
\hline Brazil & 0.18 & $\ldots$ & $\ldots$ & $\ldots$ & $\ldots$ & $\ldots$ & $\ldots$ & $\ldots$ & $\ldots$ & $\ldots$ & $\ldots$ \\
\hline China & $0.26^{*}$ & $0.19 *$ & $\ldots$ & $\ldots$ & $\ldots$ & $\ldots$ & $\ldots$ & $\ldots$ & $\ldots$ & $\ldots$ & $\ldots$ \\
\hline Colombia & 0.24 & 0.20 & 0.19 & $\ldots$ & $\ldots$ & $\ldots$ & $\ldots$ & $\ldots$ & $\ldots$ & $\ldots$ & $\ldots$ \\
\hline Former Soviet & 0.20 & 0.14 & $0.17 *$ & 0.09 & $\ldots$ & $\ldots$ & $\ldots$ & $\ldots$ & $\ldots$ & $\ldots$ & $\ldots$ \\
\hline India & $0.25^{*}$ & 0.17 & $0.17 *$ & 0.09 & 0.06 & $\ldots$ & $\ldots$ & $\ldots$ & $\ldots$ & $\ldots$ & $\ldots$ \\
\hline Iran & $0.24 *$ & $0.19 *$ & $0.12 *$ & 0.15 & 0.06 & $0.10^{*}$ & $\ldots$ & $\ldots$ & $\ldots$ & $\ldots$ & $\ldots$ \\
\hline Mexico & $0.37 *$ & $0.23 *$ & $0.18^{*}$ & $0.28 *$ & $0.14 *$ & $0.13^{*}$ & $0.06^{*}$ & $\ldots$ & $\ldots$ & $\ldots$ & $\ldots$ \\
\hline Pakistan & $0.19 *$ & $0.17 *$ & $0.16^{*}$ & 0.13 & $0.13^{*}$ & 0.14 & $0.11 *$ & $0.22 *$ & $\ldots$ & $\ldots$ & $\ldots$ \\
\hline Serbia & 0.23 & 0.20 & 0.17 & 0.16 & 0.09 & 0.21 & 0.11 & $0.27 *$ & 0.16 & $\ldots$ & $\ldots$ \\
\hline Spain & 0.11 & 0.20 & 0.19 & $0.09 *$ & 0.11 & 0.13 & $0.18 *$ & $0.33 *$ & 0.19 & 0.19 & $\ldots$ \\
\hline Turkey & $0.32 *$ & $0.21 *$ & $0.18 *$ & 0.16 & 0.06 & 0.07 & 0.00 & $0.07 *$ & 0.11 & 0.22 & 0.25 \\
\hline United States & $0.35^{*}$ & $0.24 *$ & $0.16^{*}$ & $0.21 *$ & $0.13^{*}$ & 0.08 & $0.08 *$ & $0.05^{*}$ & $0.21 *$ & $0.25^{*}$ & $0.29 *$ \\
\hline
\end{tabular}

y Categories with fewer than four lines were excluded from analyses and are not shown.

${ }^{\mathrm{z}}$ Average values for simple sequence repeats are presented; * indicates value was outside the 2.5 and $97.5 \%$ confidence intervals at 1,000 bootstraps.

TABLE 6. Genetic differentiation (Fst pairwise differentiation) of pepper genotypes among continents

\begin{tabular}{lcccc}
\hline & & \multicolumn{3}{c}{ Fst $^{\mathrm{z}}$} \\
\cline { 2 - 5 } Continent $^{\mathrm{y}}$ & Africa & Asia & Europe & \multicolumn{2}{c}{ North America } \\
\hline Asia & 0.06 & $\ldots$ & $\ldots$ & $\ldots$ \\
Europe & 0.02 & 0.02 & $\ldots$ & $\ldots$ \\
North America & $0.07^{*}$ & $0.00^{*}$ & 0.03 & $\ldots .01$ \\
South America & 0.01 & $0.05^{*}$ & $0.06^{*}$ & \\
\hline
\end{tabular}

y Categories with fewer than four lines were excluded from analyses and are not shown.

${ }^{\mathrm{z}}$ Average values for simple sequence repeats are presented; * indicates value was outside the 2.5 and $97.5 \%$ confidence intervals at 1,000 bootstraps. 
disease susceptibility, though some clusters were better represented in categories than others. Few individuals (15 of 157) were admixed, consistent with previous results that showed low levels of admixture in pepper populations $(1,20,25)$.

$C$. frutescens and $C$. chinense individuals were grouped within cluster 3 with several $C$. annuum lines. These $C$. annuum lines in cluster 3 were predominantly from South America and are likely the result of introgression or misclassification. Many of these individuals had growth habits or flower color reminiscent of $C$. frutescens or $C$. chinense species (data not shown). These data suggest limited introgression from related species into $C$. annuum within available pepper germplasm, and minimal recombination among genetic clusters, similar to previous results $(20,32)$. Using an alternate marker system with greater resolution, such as singlenucleotide polymorphisms may reveal increased genetic diversity within this population.

When grouped by geographic regions, populations in Asia and North America were represented by individuals from each $C$. annuum-specific cluster. In Asia, the small-fruited lines and landraces commonly grown may be more akin to ancestral populations or may be the result of selection for different local markets. In North America. the high genetic diversity and broad population profile are likely due to the inclusion of different market classes (sweet-fruited bell pepper and pungent chili) and breeding lines in the population $(20,34)$. Individual countries in Asia did not display the diversity seen across the continent, suggesting that the high genetic diversity of the continent may be the result of local market selections. The United States (the only country represented by four individuals in North America) was represented by multiple market classes and maintained this diverse population profile seen for North America.

Phytophthora fruit rot resistance, population structure, and genetic diversity demonstrated significant differences between countries and continents in this diverse collection of pepper fruit. Disease susceptibility was significantly associated with population structure, continents, and countries of origin at both 3 and 5 dpi. These results provide the groundwork for Phytophthora fruit rot resistance, genetic diversity, and population structure of C. annuum on a global scale. Further work is needed to identify pepper lines with full resistance to Phytophthora fruit rot. This work will provide a basis for breeding resistance and for future studies on Phytophthora fruit rot resistance and worldwide population structure of pepper.

\section{ACKNOWLEDGMENTS}

We thank S. Boyle, J. Mitchell, and J. Kurjan for technical assistance; and A. Strachota-Jacobs (Johnny's Select Seeds) for providing seed material.

\section{LITERATURE CITED}

1. Aguilar-Melendez, A., Morrell, P. L., Roose, M. L., and Kim, S.-C. 2009. Genetic diversity and structure in semiwild and domesticated chiles (Capsicum annuum; Solanaceae) from Mexico. Am. J. Bot. 96:11901202.

2. Albrecht, E., Zhang, D., Mays, A. D., Saftner, R. A., and Stommel, J. R. 2012. Genetic diversity in Capsicum baccatum is significantly influenced by its ecogeographical distribution. BMC Genet. 13:68.

3. Barksdale, T. H. 1984. Resistance to foliar blight and crown rot of pepper caused by Phytophthora capsici. Plant Dis. 68:506.

4. Benetka, V., Novotná, K., and Štochlová, P. 2012. Wild populations as a source of germplasm for black poplar (Populus nigra L.) breeding programmes. Tree Genet. Genomes 8:1073-1084.

5. Biles, C. L., Wall, M. M., Waugh, M., and Palmer, H. 1993. Relationship of Phytophthora fruit rot to fruit maturation and cuticle thickness of new Mexican-type peppers. Phytopathology 83:607-611.

6. Brachi, B., Faure, N., Horton, M., Flahauw, E., Vazquez, A., Nordborg, M., Bergelson, J., Cuguen, J., and Roux, F. 2010. Linkage and association mapping of Arabidopsis thaliana flowering time in nature. PLoS Genet. 6:e1000940.
7. Candole, B. L., Conner, P. J., and Ji, P. 2010. Screening Capsicum annuиm accessions for resistance to six isolates of Phytophthora capsici. HortScience 45:254-259.

8. Chen, X., Min, D., Yasir, T. A., and Hu, Y.-G. 2012. Genetic diversity, population structure and linkage disequilibrium in elite Chinese winter wheat investigated with SSR markers. PLoS One 7:e44510.

9. Courtois, B., Frouin, J., Greco, R., Bruschi, G., Droc, G., Hamelin, C., Ruiz, M., Clément, G., Evrard, J.-C., van Coppenole, S., Katsantonis, D., Oliveira, M., Negrão, S., Matos, C., Cavigiolo, S., Lupotto, E., Piffanelli, P., and Ahmadi, N. 2012. Genetic diversity and population structure in a European collection of rice. Crop Sci. 52:1663.

10. Diamanti, J., Capocasa, F., Balducci, F., Battino, M., Hancock, J., and Mezzetti, B. 2012. Increasing strawberry fruit sensorial and nutritional quality using wild and cultivated germplasm. PLoS One 7:e46470.

11. Evanno, G., Regnaut, S., and Goudet, J. 2005. Detecting the number of clusters of individuals using the software structure: A simulation study. Mol. Ecol. 14:2611-2620.

12. Falush, D., Stephens, M., and Pritchard, J. K. 2003. Inference of population structure using multilocus genotype data: Linked loci and correlated allele frequencies. Genetics 164:1567-1587.

13. Fonseca, R. M., Lopes, R., Barros, W. S., Lopes, M. T. G., and Ferreira, F. M. 2008. Morphologic characterization and genetic diversity of Capsicum chinense Jacq. accessions along the upper Rio Negro-Amazonas. Crop Breed. Appl. Biotechnol.p8:187-194.

14. Foster, J. M., and Hausbeck, M. K. 2010. Resistance of Pepper to Phytophthora crown, root, and fruit rot is affected by isolate virulence. Plant Dis. 94:24-30.

15. Granke, L. L., Quesada-Ocampo, L. M., Lamour, K., and Hausbeck, M. Advances in research on Phytophthora capsici on vegetable crops in the United States. Plant Dis. 96:1588-1600.

16. Greenleaf, W. 1985. Pepper breeding. Pages 68-80 in: Breeding Vegetable Crops. Springer, New York.

17. Hale, M. L., Burg, T. M., and Steeves, T. E. 2012. Sampling for microsatellite-based population genetic studies: 25 to 30 Individuals per population is enough to accurately estimate allele frequencies. PLoS One 7:e45170.

18. Hartl, D. L., and Clark, A. G. 2007. Principles of Population Genetics, 4th ed. Sinauer Associates, Inc. Publishers, Sunderland, MA.

19. Hernández-Verdugo, S., Luna-Reyes, R., and Oyama, K. 2001. Genetic structure and differentiation of wild and domesticated populations of Capsicum annuum (Solanaceae) from Mexico. Plant Syst. Evol. 226:129142.

20. Hill, T. A., Ashrafi, H., Reyes-Chin-Wo, S., Yao, J., Stoffel, K., Truco, M.-J., Kozik, A., Michelmore, R. W., and Van Deynze, A. 2013. Characterization of Capsicum annuum genetic diversity and population structure based on parallel polymorphism discovery with a $30 \mathrm{~K}$ unigene pepper GeneChip. PLoS One 8:e56200.

21. Ibiza, V. P., Blanca, J., Cañizares, J., and Nuez, F. 2012. Taxonomy and genetic diversity of domesticated Capsicum species in the Andean region. Genet. Resour. Crop Evol. 59:1077-1088.

22. Jones, D., Jones, G. A., Hagen, T., and Creech, E. 1985. Wild species of Nicotiana as a new source of tobacco resistance to the tobacco hornworm Manduca sexta. Entomol. Exp. Appl. 38:157-164.

23. Kang, H. M., Zaitlen, N. A., Wade, C. M., Kirby, A., Heckerman, D., Daly, M. J., and Eskin, E. 2008. Efficient control of population structure in model organism association mapping. Genetics 178:1709-1723.

24. Kimble, K., and Grogan, R. 1960. Resistance to Phytophthora root rot in pepper. Phytopathology 50:642-642.

25. Konisho, K., Minami, M., Matsushima, K., and Nemoto, K. 2005. Phylogenetic relationship and species identification by RAPD analysis in genus Capsicum. Hortic. Res. (Japan) 4:259-264.

26. Liu, K., and Muse, S. V. 2005. PowerMarker: An integrated analysis environment for genetic marker analysis. Bioinformatics 21:2128-2129.

27. McGregor, C., Waters, V., Nambeesan, S., MacLean, D., Candole, B. L., and Conner, P. 2011. Genotypic and phenotypic variation among pepper accessions resistant to Phytophthora capsici. HortScience 46:1235-1240.

28. Minamiyama, Y., Tsuro, M., Kubo, T., and Hirai, M. 2007. QTL Analysis for resistance to Phytophthora capsici in pepper using a high density SSR-based map. Breed. Sci. 57:129-134.

29. Moses, M., and Umaharan, P. 2012. Genetic structure and phylogenetic relationships of Capsicum chinense. J. Am. Soc. Hortic. Sci. 137:250-262.

30. Naegele, R. P., Ashrafi, H., Hill, T. A., Reyes Chin-Wo, S., Van Deynze, A. E., and Hausbeck, M. K. 2014. QTL mapping of fruit rot resistance to the plant pathogen Phytophthora capsici Leonian in a recombinant inbred line Capsicum annuum L. population. Phytopathology 104:479-483.

31. Oyama, K., Hernández-Verdugo, S., Sánchez, C., González-Rodríguez, A., Sánchez-Peña, P., Garzón-Tiznado, J. A., and Casas, A. 2006. Genetic structure of wild and domesticated populations of Capsicum annиит (Solanaceae) from northwestern Mexico analyzed by RAPDs. Genet. Resour. Crop Evol. 53:553-562. 
32. Pacheco-Olvera, A., Hernández-Verdugo, S., Rocha-Ramírez, V., González-Rodríguez, A., and Oyama, K. 2012. Genetic diversity and structure of pepper (Capsicum аппиит L.) from Northwestern Mexico analyzed by microsatellite markers. Crop Sci. 52:231.

33. Perry, L., Dickau, R., Zarrillo, S., Holst, I., Pearsall, D. M., Piperno, D. R., Berman, M. J., Cooke, R. G., Rademaker, K., Ranere, A. J., Raymond, J. S., Sandweiss, D. H., Scaramelli, F., Tarble, K., and Zeidler, J. A. 2007. Starch fossils and the domestication and dispersal of chili peppers (Capsicum spp. L.) in the Americas. Science 315:986-988.

34. Pickersgill, B. 1997. Genetic resources and breeding of Capsicum spp. Euphytica 96:129-133.

35. Pritchard, J. K., Stephens, M., and Donnelly, P. 2000. Inference of population structure using multilocus genotype data. Genetics 155:945-959.

36. R Development Core Team. 2012. R: A Language and Environment for Statistical Computing. R Foundation for Statistical Computing, Vienna. http://www.r-project.org/

37. Rodriguez, J. M., Berke, T., Engle, L., and Nienhuis, J. 1999. Variation among and within Capsicum species revealed by RAPD markers. Theor. Appl. Genet. 99:147-156.

38. Sage-Palloix, A. M., Jourdan, F., Phaly, T., Nemouchi, G., Lefebvre, V., and Palloix, A. 2007. Analysis of Diversity in Pepper Genetic Resources: Distribution of Horticultural and Resistance Traits in the INRA Pepper Germplasm. Pages 33-42 in: Progress in Research on Capsicum and Eggplant. K. Niemirowicz-Szezytt, ed. Proceedings of the XIIth Eucarpia Meeting, Warsaw, Poland.

39. Saini, S. S., and Sharma, P. P. 1978. Inheritance of resistance to fruit rot
(Phytophthora capsici Leon.) and induction of resistance in bell pepper (Capsicum annuum L.). Euphytica 27:721-723.

40. Spooner, D. M., and Bamberg, J. B. 1994. Potato genetic resources: Sources of resistance and systematics. Am. Potato J. 71:325-337.

41. Sy, O., Bosland, P. W., and Steiner, R. 2005. Inheritance of Phytophthora stem blight resistance as compared to Phytophthora root rot and Phytophthora foliar blight resistance in Capsicum annuum L. J. Am. Soc. Hortic. Sci. 130:75-78

42. Wahyuni, Y., Ballester, A.-R., Tikunov, Y., Vos, R. C. H. de, Pelgrom, K. T. B., Maharijaya, A., Sudarmonowati, E., Bino, R. J., and Bovy, A. G. 2013. Metabolomics and molecular marker analysis to explore pepper (Capsicum sp.) biodiversity. Metabolomics 9:130-144.

43. Walker, S. J., and Bosland, P. W. 1999. Inheritance of Phytophthora root rot and foliar blight resistance in pepper. J. Am. Soc. Hortic. Sci. 124:1418 .

44. Waterhouse, G. M. 1963. Key to the Species of Phytophthora de Bary. Commonwealth Mycological Society, Kew, Surrey, UK.

45. Xu, J., Ranc, N., Muños, S., Rolland, S., Bouchet, J.-P., Desplat, N., Paslier, M.-C. L., Liang, Y., Brunel, D., and Causse, M. 2013. Phenotypic diversity and association mapping for fruit quality traits in cultivated tomato and related species. Theor. Appl. Genet. 126:567-581.

46. Zhao, K., Tung, C.-W., Eizenga, G. C., Wright, M. H., Ali, M. L., Price, A. H., Norton, G. J., Islam, M. R., Reynolds, A., Mezey, J., McClung, A. M., Bustamante, C. D., and McCouch, S. R. 2011. Genome-wide association mapping reveals a rich genetic architecture of complex traits in Oryza sativa. Nat. Commun. 2:467. 